\title{
Article \\ High Efficiency In Vitro Wound Healing of Dictyophora indusiata Extracts via Anti-Inflammatory and Collagen Stimulating (MMP-2 Inhibition) Mechanisms
}

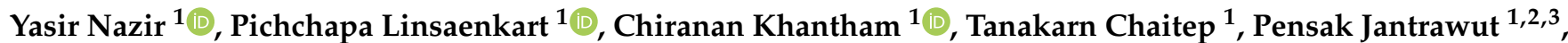

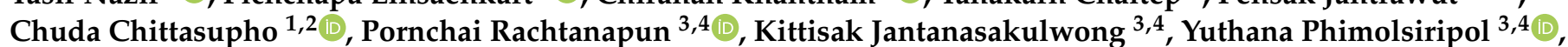 \\ Sarana Rose Sommano ${ }^{2,3} \mathbb{D}^{\mathbb{D}}$, Jiraporn Tocharus ${ }^{5}$, Salin Mingmalairak ${ }^{5}$, Anchali Wongsa ${ }^{6}$, Chaiwat Arjin $6{ }^{6}$,

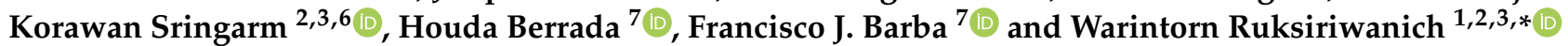

1 Department of Pharmaceutical Sciences, Faculty of Pharmacy, Chiang Mai University, Chiang Mai 50200, Thailand; ynchem@yahoo.com (Y.N.); pichchapa_li@cmu.ac.th (P.L.); ckhantham@gmail.com (C.K.); tanakarn_c@cmu.ac.th (T.C.); pensak.j@cmu.ac.th (P.J.); chuda.c@cmu.ac.th (C.C.)

2 Cluster of Research and Development of Pharmaceutical and Natural Products Innovation for Human or Animal, Chiang Mai University, Chiang Mai 50200, Thailand; sarana.s@cmu.ac.th (S.R.S.); korawan.s@cmu.ac.th (K.S.)

check for updates

Citation: Nazir, Y.; Linsaenkart, P.; Khantham, C.; Chaitep, T.; Jantrawut, P.; Chittasupho, C.; Rachtanapun, P.; Jantanasakulwong, K.; Phimolsiripol, Y.; Sommano, S.R.; et al. High Efficiency In Vitro Wound Healing of Dictyophora indusiata Extracts via Anti-Inflammatory and Collagen Stimulating (MMP-2 Inhibition) Mechanisms. J. Fungi 2021, 7, 1100. https://doi.org/10.3390/jof7121100

\section{Academic Editors:}

Jasmina Glamočlija and Dejan Stojković

Received: 22 November 2021 Accepted: 17 December 2021 Published: 20 December 2021

Publisher's Note: MDPI stays neutral with regard to jurisdictional claims in published maps and institutional affiliations.

Copyright: (C) 2021 by the authors Licensee MDPI, Basel, Switzerland. This article is an open access article distributed under the terms and conditions of the Creative Commons Attribution (CC BY) license (https:// creativecommons.org/licenses/by/ $4.0 /)$.
3 Cluster of Agro Bio-Circular-Green Industry, Faculty of Agro-Industry, Chiang Mai University, Chiang Mai 50100, Thailand; pornchai.r@cmu.ac.th (P.R.); jantanasakulwong.k@gmail.com (K.J.); yuthana.p@cmu.ac.th (Y.P.)

4 Faculty of Agro-Industry, Chiang Mai University, Chiang Mai 50100, Thailand

5 Faculty of Medicine, Chiang Mai University, Chiang Mai 50200, Thailand; jiraporn.tocharus@cmu.ac.th (J.T.); mingmalairak_s@yahoo.com (S.M.)

6 Department of Animal and Aquatic Sciences, Faculty of Agriculture, Chiang Mai University, Chiang Mai 50200, Thailand; awongsa@hotmail.com (A.W.); chaiwat_arjin@cmu.ac.th (C.A.)

7 Department of Preventive Medicine and Public Health, Food Science, Toxicology and Forensic Medicine, Faculty of Pharmacy, Universitat de València, 46100 Valencia, Spain; houda.berrada@uv.es (H.B.); francisco.barba@uv.es (F.J.B.)

* Correspondence: warintorn.ruksiri@cmu.ac.th; Tel.: +66-96269-5354

Abstract: Dictyophora indusiata or Phallus indusiatus is widely used as not only traditional medicine, functional foods, but also, skin care agents. Biological activities of the fruiting body from $D$. indusiata were widely reported, while the studies on the application of immature bamboo mushroom extracts were limited especially in the wound healing effect. Wound healing process composed of 4 stages including hemostasis, inflammation, proliferation, and remodelling. This study divided the egg stage of bamboo mushroom into 3 parts: peel and green mixture (PGW), core (CW), and whole mushroom (WW). Then, aqueous extracts were investigated for their nucleotide sequencing, biological compound contents, and wound healing effect. The anti-inflammatory determination via the levels of cytokine releasing from macrophages, and the collagen stimulation activity on fibroblasts by matrix metalloproteinase-2 (MMP-2) inhibitory activity were determined to serve for the wound healing process promotion in the stage $2-4$ (wound inflammation, proliferation, and remodelling of the skin). All D. indusiata extracts showed good antioxidant potential, significantly anti-inflammatory activity in the decreasing of the nitric oxide (NO), interleukin-1 (IL-1), interleukin-1 (IL-6), and tumour necrosis factor- $\alpha$ (TNF- $\alpha$ ) secretion from macrophage cells $(p<0.05)$, and the effective collagen stimulation via MMP-2 inhibition. In particular, CW extract containing high content of catechin $(68.761 \pm 0.010 \mathrm{mg} / \mathrm{g}$ extract) which could significantly suppress NO secretion $(0.06 \pm 0.02 \mu \mathrm{mol} / \mathrm{L})$ better than the standard anti-inflammatory drug diclofenac $(0.12 \pm 0.02 \mu \mathrm{mol} / \mathrm{L})$ and their MMP-2 inhibition $(41.33 \pm 9.44 \%)$ was comparable to L-ascorbic acid $(50.65 \pm 2.53 \%)$. These findings support that $\mathrm{CW}$ of $D$. indusiata could be an essential natural active ingredient for skin wound healing pharmaceutical products.

Keywords: anti-inflammatory; bamboo mushroom; collagen stimulating activity; Dictyophora indusiata; matrix metalloproteinase-2 activity; wound healing 


\section{Introduction}

Mushroom is rich in nutrients and bioactive compounds. Edible mushroom is regularly being used as food, dietary supplements as well as cosmeceutical products such as anti-ageing, moisturizing, and skin lightening. Since, mushroom polysaccharides and polyphenol contents were involved in antioxidant and immunomodulatory activities [1,2]. Dictyophora indusiata or Phallus indusiatus or bamboo mushroom is a fungus belonging to the family Phallaceae. The bioactive compositions in immature and mature stages of this mushroom are different. The egg or immature mushroom produces viscous mucilage and high phenolic contents $[3,4]$. The mature stage of this mushroom contains many bioactive compounds, for example, polysaccharides, amino acids, terpenoids, and alkaloids [5,6]. Many studies revealed that the fruiting body of $D$. indusiata showed various impressive activities such as anti-obesity [7], and neuroprotective effect for treating Alzheimer's disease [8]. Furthermore, $D$. indusiata also has considerable bioactivities with cosmeceutical potentials such as antioxidant, anti-tyrosinase, antimicrobial properties [9-11]. Interestingly, most research papers reported that polysaccharides from the fruiting body of $D$. indusiata contributed to immune modulation [12-14] and considered as a nutraceutical supplement in Chinese remedy. The superior anti-inflammatory activity of $D$. indusiata can be applied both via the oral and topical routes. Since the skin inflammation is a process that happens when the skin is damaged and wounded.

The skin wound repairing process included 4 main approaches, hemostasis, inflammation, proliferation, and tissue remodelling. Firstly, fibrin formation is the crucial step in coagulation cascades to stop blood loss [15]. During this phase, the number of soluble mediators such as platelet-derived growth factor (PDGF), insulin-like growth factor1 (IGF-1), epidermal growth factor (EGF), fibroblast growth factor (FGF), transforming growth factor- $\beta$ (TGF- $\beta$ ), and vascular endothelial cell growth factor (VEGF) are released from platelets [16]. Secondly, inflammation phase, macrophages migrate and defend microbes, attract other macrophage cells, and secrete cytokines and protease (elastase and collagenase) which degrade the skin extracellular matrix (ECM) components [17]. Inflammatory cytokines containing interleukin-1 (IL-1) and tumour necrosis factor- $\alpha$ (TNF- $\alpha$ ) activated proteases production and apoptosis in fibroblasts. Thirdly, the promotion of cell proliferation and restoration of the matrix, fibroblasts, endothelial cells, and keratinocytes in tissue remodelling are conducted. Growth factors and cytokines are synthesized to promote cell proliferation, develop new capillary formation, and produce new ECM components $[18,19]$. Subsequently, matrix metalloproteinases (MMPs) will remove injured matrix proteins and then fibroblasts release lysyl oxidase to link collagen at ECM in the scar forming.

However, the most common wound-healing problem is the hypertrophic scar or keloid resulting from prolonged inflammation [20] and the action of matrix metalloproteinases enzymes [15]. Thus, the suppression of the inflammatory cytokines improves skin structure and barrier functions in the skin wounds [21] and MMP-2 inhibitory potential could restore the balance of collagen production [22] resulting in the successful wound healing process without the hypertrophic scar.

Moreover, most research papers reported various bioactivities of the fruiting body from $D$. indusiata, while the studies on the application of immature bamboo mushroom extracts as cosmeceutical or pharmaceutical applications were only a few. Therefore, this study aimed to investigate total phenolic, flavonoid, and polysaccharide contents, then further determine the antioxidant capabilities of aqueous extracts from 3 parts of $D$. indusiata mushroom. In addition, these extracts were assessed for wound healing activity using RAW 264.7 macrophages and $h T R T$ fibroblasts which compared to the standard substances. The results from this study may consider as bioactive sources for pharmaceutical and/or cosmeceutical applications. 


\section{Results and Discussion}

\subsection{Identification of Dictyophora indusiata}

\subsubsection{Specific Primers Designing and Selection}

The primers: $18 \mathrm{~S}$ ribosomal DNA (rDNA)-internal transcribed spacer 1 (ITS 1)-5.8S rDNA-internal transcribed spacer 2 (ITS 2)-28S rDNA and ITS1-5.8S rDNA-ITS2 sequences were obtained from D. indusiata f. lutea [23] and D. indusiata strain ASI 32001 [24], respectively. The designed specific primers for the identification of the sample are illustrated in Table 1. The PCR products of the sample gave one band with the expected size of $107 \mathrm{bp}$ (Dict 01 primer), $150 \mathrm{bp}$ (Dict 03 primer), $650 \mathrm{bp}$ (Dict 04 primer), and $100 \mathrm{bp}$ (Dict 05 primer), respectively. Although, Dict 02 and Dict 06 primers could not amplify DNA from the sample. The gel purified PCR products are represented in Figure 1. Therefore, the specific primers: Dict 03 and Dict 04 were chosen to identify the sample further.

Table 1. Primer sequences for sample amplification.

\begin{tabular}{|c|c|c|c|}
\hline Primer Code Name & Primer Sequences $\left(5^{\prime}-3^{\prime}\right)$ & Size of Product (bp) & References \\
\hline Dict 01: forward & AGGCCTCTCGAAAGAGGGTC & 20 & \multirow{2}{*}{ [23] } \\
\hline Dict 01: reverse & TCATCGATGCGAAAGCCAAG & 20 & \\
\hline Dict 02: forward & TCGCGCGTGTCAGTGAAATA & 20 & \multirow{2}{*}{ [23] } \\
\hline Dict 02: reverse & CCAAGTCCGAAAGGGGTCTC & 20 & \\
\hline Dict 03: forward & TGCCTGTTTGAGTGTCGTGA & 20 & \multirow{2}{*}{ [23] } \\
\hline Dict 03: reverse & ACGGACGACGCAAGACTTAT & 20 & \\
\hline Dict 04: forward & GGAAGTAAAAGTCGTAACAAGG & 22 & \multirow{2}{*}{ [23] } \\
\hline Dict 04: reverse & TCCTCCGCTTATTGATATGC & 20 & \\
\hline Dict 05: forward & AGGAGCATGCCTGTTTGAGT & 20 & \multirow{2}{*}{ [24] } \\
\hline Dict 05: reverse & TGGAAACCTCGCCGATGAAT & 20 & \\
\hline Dict 06: forward & GTCATGAACGCCCGTTTCTC & 20 & \multirow{2}{*}[24]{} \\
\hline Dict 06: reverse & ACССТССТTCCGATGAGACT & 20 & \\
\hline
\end{tabular}

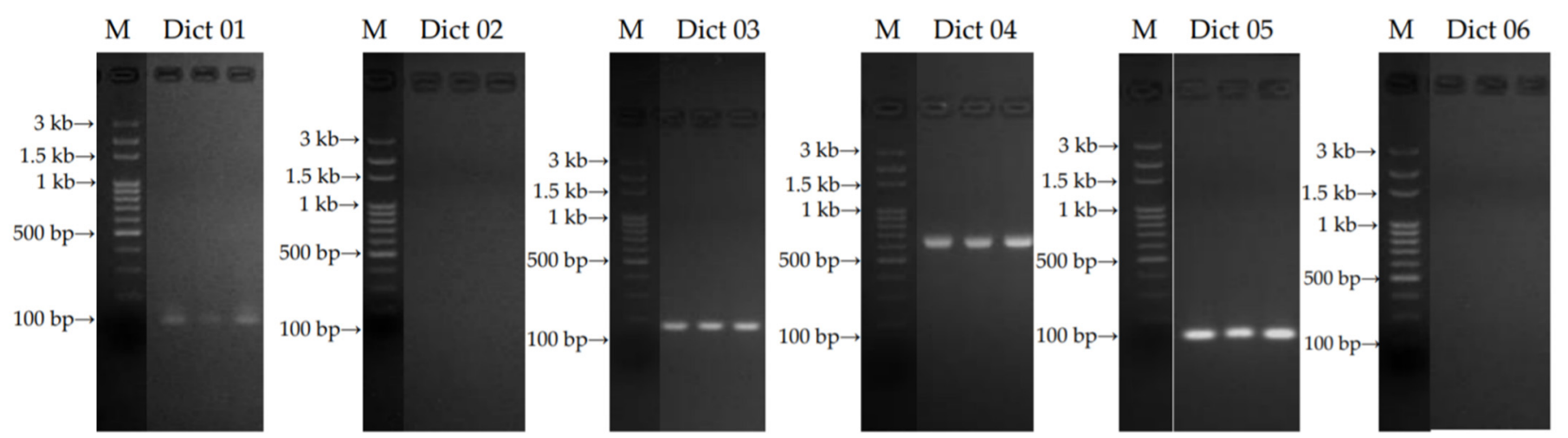

Figure 1. PCR products of the sample from the 6 specific primers (Dict 01, 02, 03, 04, 05 and 06 primers); marker lane (M).

\subsubsection{Nucleotide Sequences and Phylogenetic Relationships}

The complete nucleotide sequences resulting from Dict 03 primer and Dict 04 primer are illustrated in Table 2. The sequences of the sample were blasted compared to the sequences of the available fungi species from GenBank. The nucleotide sequences resulting from Dict 03 primer matched 98\% Dictyophora indusiata strain ZS03 (accession number MH464257.1), Dictyophora echinovolvata strain ASI 32010 (accession number AF324167.2), and Dictyophora echinovolvata strain ASI 32002 (accession number AF324164.2). The sequences of the sample also belonged to Phallus echinovolvatus voucher GDGM 79013 (accession number MN613536.1), Phallus echinovolvatus strain GDGM 79020 (accession number MN523216.1), Dictyophora echinovolvata strain ASI 32014 (accession number AF324168.2), 
Dictyophora echinovolvata strain ASI 32007 (accession number AF324165.2), and Dictyophora echinovolvata strain ASI 32008 (accession number AF324166.2) (97\% identity) which obtained from Dict 04 primer. Furthermore, the percentages of nucleotide identity between the sample in the present study and the fungi species obtained from GenBank are displayed in Tables 3 and 4 . The phylogenetic trees were assessed using the genetic distances from neighbor joining (NJ) method with 1000 bootstrap replications. The trees are presented in Figures 2 and 3.

Table 2. Nucleotide sequences of the sample.

\begin{tabular}{|c|c|c|}
\hline Specific Primer & Sequences $\left(5^{\prime}-3^{\prime}\right)$ & Size (bp) \\
\hline Dict 03 & $\begin{array}{l}\text { TTACCGAAGGAGGCAGGACTAACAAGTTCGGAAGGGGGGTAAAGGGGAAGGG } \\
\text { GGACCTTCGCCGATGAATTTGAAGACGAGCCTTCGACCGCAGGGGGATTCGAG } \\
\text { GGCAAGACCGTCCAAGTCCGAAAAAAGGAGAAATCCGTTAA }\end{array}$ & 146 \\
\hline Dict 04 & $\begin{array}{l}\text { TTCCTTCCTTTCCTCCGCTTATTGATATGATTAAGTTGGGCGGGTAATCCTGCCTG } \\
\text { ATTTGAGGTCAAGGCGTATAATGAATGACGGAACGAGAAGCCCACCCCGCCCT } \\
\text { TTTTTTCCCCCAGGACGAAGCAAGACTTATCAAGTTTGGATGGGGGGTAAAG } \\
\text { GGGAAGGGGGACCTTCGCCGATGAATTGAAGACGAGCCTTCGACCGCAGGGG } \\
\text { GATTGGAGGGCAAGACCGTCCAAGTCAAGAAAAAAGGGAGAAATCCTTTTT } \\
\text { CGATGAGATTCACGACACTCAAACAGGCATGCTCCTCGGAATACCGAGGAGC } \\
\text { GCAAGATGCGTTCAAAGATTCGATGATTCATTGAATCTGCAATTCACATTACG } \\
\text { TTTCGCGCGTTCGCGGCGTTCTTCATCGATGCGAAAGCCAAGAGATCCGTTGTT } \\
\text { GAAAGTTGTGTTTCGATTTTATTCACTGACACGCGCGAGACTGCGAGGCGTTT } \\
\text { GTGAAAGACGGGAGGGGCCAAGCCTCTTTCGAGAGGCCTCTCCCAGAGTGCAC } \\
\text { GGAGGTGTCGGTCGGGGAGAGAGAGCGCGTCTCCCCCCGGATGATAAATCGG } \\
\text { CAATGATCTCCGCAGTACAGAG }\end{array}$ & 613 \\
\hline
\end{tabular}

Table 3. Nucleotide identity between the nucleotide sequences of the sample resulting from Dict 03 primer and the fungi species.

\begin{tabular}{ccc}
\hline Species & GenBank Accession Number & Nucleotide Identity (\%) \\
\hline Dictyophora indusiata strain ZS03 & MH464257.1 & 98 \\
Dictyophora echinovolvata strain ASI 32010 & AF324167.2 & 98 \\
Dictyophora echinovolvata strain ASI 32002 & AF324164.2 & 98 \\
Phallus echinovolvatus voucher GDGM 79013 & MN613536.1 & 97 \\
Phallus echinovolvatus strain GDGM 79020 & MN523216.1 & 97 \\
Dictyophora echinovolvata strain ASI 32014 & AF324168.2 & 97 \\
Dictyophora sp. voucher KHTH09070 & MG678511.1 & 97 \\
Dictyophora indusiata f. lutea & HQ414538.1 & 95 \\
\hline
\end{tabular}

Table 4. Nucleotide identity between the nucleotide sequences of the sample resulting from Dict 04 primer and the fungi species.

\begin{tabular}{ccc}
\hline Species & GenBank Accession Number & Nucleotide Identity (\%) \\
\hline Phallus echinovolvatus voucher GDGM 79013 & MN613536.1 & 97 \\
Phallus echinovolvatus strain GDGM 79020 & MN523216.1 & 97 \\
Dictyophora echinovolvata strain ASI 32014 & AF324168.2 & 97 \\
Dictyophora echinovolvata strain ASI 32007 & AF324165.2 & 97 \\
Dictyophora echinovolvata strain ASI 32008 & AF324166.2 & 97 \\
Dictyophora echinovolvata strain ASI 32010 & AF324167.2 & 95 \\
Dictyophora echinovolvata strain ASI 32002 & AF324164.2 & 95 \\
\hline
\end{tabular}




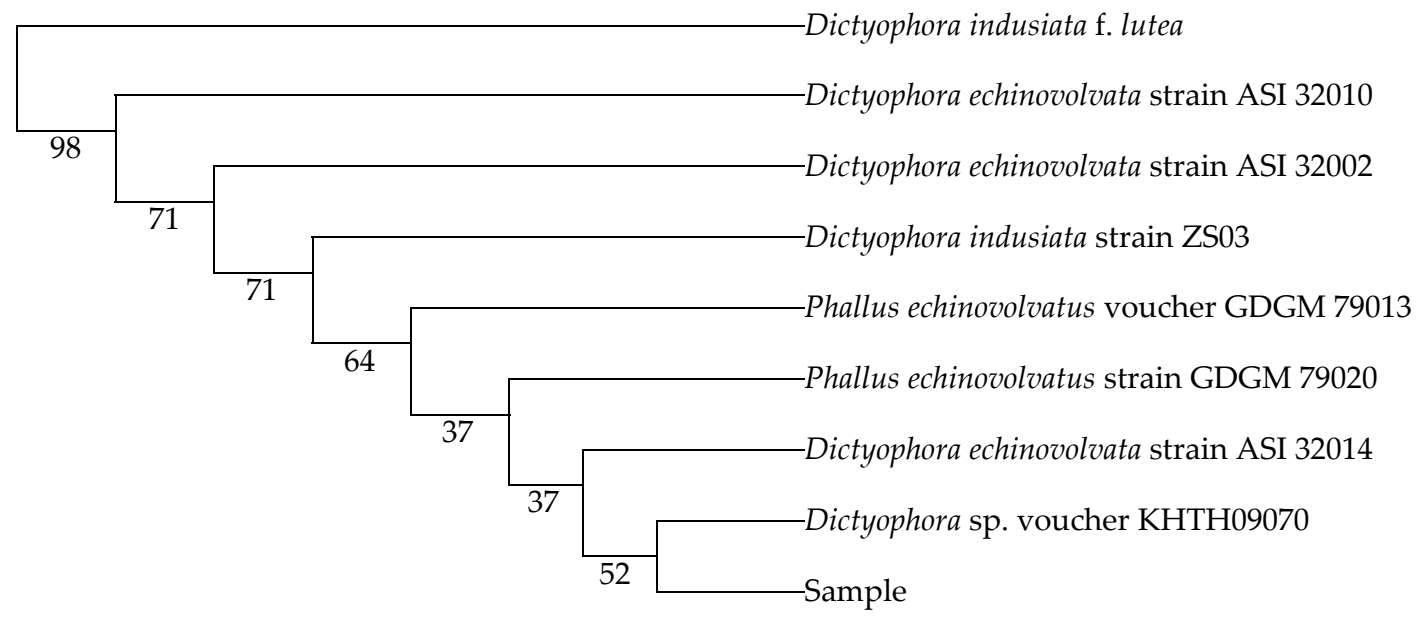

Figure 2. The phylogenetic tree of the sample resulting from Dict 03 primer. Neighbor joining: bootstrap analysis (1000 replications) by MEGA X.

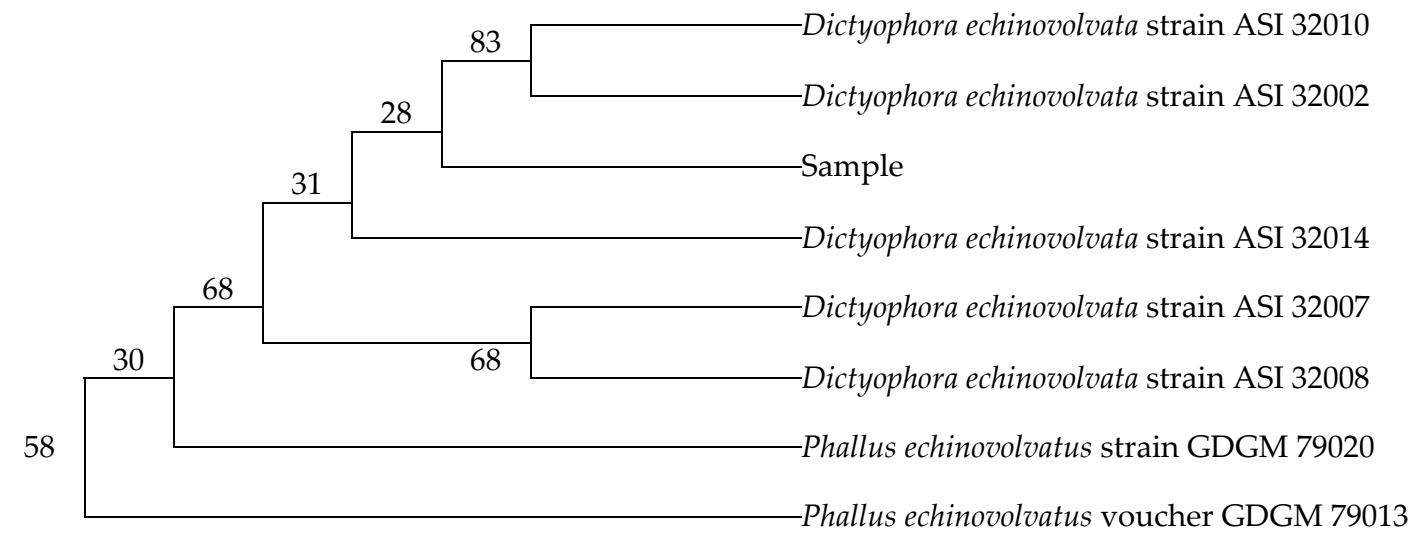

Figure 3. The phylogenetic tree of the sample resulting from Dict 04 primer. Neighbor joining: bootstrap analysis (1000 replications) by MEGA X.

\subsection{Bioactive Compounds and Antioxidant Activities}

The $D$. indusiata extracts were prepared from the immature stage of mushroom after water extraction. The extraction yields of PGW, CW and WW were $21.11 \%, 51.48 \%$ and $10.15 \%$ of dry weight, respectively. The amount of bioactive compound from the 3 types of egg D. indusiata extracts is illustrated in Table 5. The major component from immature bamboo mushroom was phenolic compound followed by polysaccharide and flavonoid, respectively. The polyphenol compositions were presented in Table 6. Catechin $(68.761 \pm 0.010 \mathrm{mg} / \mathrm{g}$ extract) was a dominant compound in the $\mathrm{CW}$, followed by $p$-coumaric acid (7.931 $\pm 0.939 \mathrm{mg} / \mathrm{g}$ extract). Nevertheless, the major polyphenol component of PGW and WW was $p$-coumaric acid. In contrast, the previous study reported that the $\beta$-D-glucan polysaccharide backbone, monosaccharide compositions of glucose, mannose, and galactose were found in the aqueous extract of $D$. indusiata fruiting body that prepared by water extraction [5]. 
Table 5. Bioactive contents of 3 types of Dictyophora indusiata aqueous extracts.

\begin{tabular}{cccc}
\hline Sample & $\begin{array}{c}\text { Total Phenolic Contents } \\
\text { (mg GAE/g Extract) }\end{array}$ & $\begin{array}{c}\text { Total Flavonoid Contents } \\
\text { (mg CE/g Extract) }\end{array}$ & $\begin{array}{c}\text { Total Polysaccharide } \\
\text { Contents }(\boldsymbol{\mu g} \text { GE/g Extract) }\end{array}$ \\
\hline PGW & $2.55 \pm 0.36$ & $0.05 \pm 0.02$ & $2.22 \pm 0.29$ \\
CW & $2.05 \pm 0.08$ & $0.01 \pm 0.02$ & $1.20 \pm 0.14$ \\
WW & $1.89 \pm 0.17$ & $0.02 \pm 0.01$ & $1.65 \pm 0.09$ \\
\hline
\end{tabular}

Each value is expressed as mean $\pm \mathrm{SD}(n=3)$; peel and green mixture (PGW); core $(\mathrm{CW})$; whole $(\mathrm{WW})$; $\mathrm{mg} \mathrm{GAE} / \mathrm{g}$ extract $=\mathrm{mg}$ of gallic acid equivalents per $\mathrm{g}$ of dry extract; $\mathrm{mg} \mathrm{CE} / \mathrm{g}$ extract $=\mathrm{mg}$ of catechin equivalents per $\mathrm{g}$ of dry weight of each extract; $\mu \mathrm{g} \mathrm{GE} / \mathrm{g}$ extract $=\mu \mathrm{g}$ of glucose equivalents per $\mathrm{g}$ of dry weight of each extract.

Table 6. Polyphenol compounds of 3 types of Dictyophora indusiata aqueous extracts.

\begin{tabular}{cccc}
\hline Polyphenol Compounds (mg/g Extract) & PGW & CW & WW \\
\hline Catechin & $3.481 \pm 0.001$ & $68.761 \pm 0.010$ & $2.934 \pm 0.010$ \\
$p$-Coumaric acid & $3.887 \pm 0.043$ & $7.931 \pm 0.939$ & $4.066 \pm 0.079$ \\
Rutin & $0.476 \pm 0.092$ & $2.502 \pm 0.008$ & $3.290 \pm 0.027$ \\
Rosmarinic acid & $3.270 \pm 0.014$ & $0.235 \pm 0.009$ & $0.178 \pm 0.006$ \\
Quercetin & $0.754 \pm 0.007$ & $0.055 \pm 0.004$ & $0.833 \pm 0.013$ \\
Naringenin & $\mathrm{Nd}$ & $0.516 \pm 0.003$ & $0.209 \pm 0.000$ \\
Epigallocatechin gallate (EGCG) & $\mathrm{Nd}$ & $0.767 \pm 0.004$ & $\mathrm{Nd}$ \\
\hline
\end{tabular}

Each value is expressed as mean $\pm \mathrm{SD}(n=3)$; peel and green mixture (PGW); core $(\mathrm{CW})$; whole $(\mathrm{WW})$; Nd = Not determined.

In the current study, PGW showed not only the highest contents of phenolic $(2.55 \pm 0.36 \mathrm{mg} \mathrm{GAE} / \mathrm{g}$ extract), flavonoid ( $0.05 \pm 0.02 \mathrm{mg} \mathrm{CE} / \mathrm{g}$ extract), and polysaccharide $(2.22 \pm 0.29 \mu \mathrm{g} \mathrm{GE} / \mathrm{g}$ extract) but also the highest FRAP value as $6.18 \pm 0.08 \mu \mathrm{M}$ $\mathrm{Fe}^{2+} / \mathrm{g}$ extract. However, the PGW also has lower activity than medical plant extract for DPPH, ABTS, and FRAP $[25,26]$. Moreover, CW presented greater antioxidant potency (DPPH assay, ABTS assay and metal chelation) than PGW, which may be due to a high catechin content, as the results of their antioxidant activities are summarized in Table 7.

Table 7. Antioxidant activities of 3 types of Dictyophora indusiata aqueous extracts.

\begin{tabular}{|c|c|c|c|c|}
\hline Sample & $\begin{array}{c}\text { DPPH Scavenging } \\
\text { Activity } \\
\left(\mathrm{SC}_{50}, \mathrm{mg} / \mathrm{mL}\right)\end{array}$ & $\begin{array}{c}\text { ABTS Scavenging } \\
\text { Activity } \\
\left(\mathrm{SC}_{50}, \mathrm{mg} / \mathrm{mL}\right)\end{array}$ & $\begin{array}{c}\text { Metal Chelating } \\
\text { Activity } \\
\left(\mathrm{MC}_{90}, \mathrm{mg} / \mathrm{mL}\right)\end{array}$ & $\begin{array}{c}\text { FRAP Reducing } \\
\text { Power } \\
\left(\mu \mathrm{M} \mathrm{Fe}^{2+} / \mathrm{g} \text { Extract) }\right.\end{array}$ \\
\hline PGW & $2.51 \pm 0.05 *$ & $8.52 \pm 0.09$ & $32.18 \pm 0.23 *$ & $6.18 \pm 0.08$ \\
\hline $\mathrm{CW}$ & $1.54 \pm 0.02 *$ & $6.51 \pm 0.08$ & $5.11 \pm 0.45^{*}$ & $2.13 \pm 0.09$ \\
\hline WW & $3.59 \pm 0.02 *$ & $11.81 \pm 0.09$ & $34.58 \pm 0.39 *$ & $3.00 \pm 0.03$ \\
\hline EDTA & $\mathrm{Nd}$ & $\mathrm{Nd}$ & $0.10 \pm 0.09$ & $\mathrm{Nd}$ \\
\hline L-ascorbic acid & $0.26 \pm 0.02$ & $\mathrm{Nd}$ & $\mathrm{Nd}$ & $\mathrm{Nd}$ \\
\hline
\end{tabular}

Each value is expressed as mean $\pm \mathrm{SD}(n=3)$; peel and green mixture (PGW); core (CW); whole (WW). Ethylenediaminetetraacetic acid (EDTA); $\mathrm{SC}_{50}=$ the concentration providing $50 \%$ scavenging activity $(\mathrm{mg} / \mathrm{mL}) ; \mathrm{MC}_{90}=$ the concentration providing $90 \%$ chelating activity $(\mathrm{mg} / \mathrm{mL}) ; \mu \mathrm{M} \mathrm{Fe}^{2+} / \mathrm{g}$ extract $=\mu \mathrm{M}$ of ferrous ion per $\mathrm{g}$ of extract; $\mathrm{Nd}=$ Not determined. Significant differences are indicated as ${ }^{*} p<0.05$ (compare to the standard substances).

DPPH radical scavenging assay measured antioxidant capacity from reducing the deep violet colour of the stable DPPH radicals to the yellow colour of nonradical DPPH [27]. The hydrogen-donating compounds such as ferulic acid, $\gamma$-oryzanol, unsaturated fatty acid, polysaccharide could scavenge the DPPH radical to nonradical form [28,29]. For $\mathrm{ABTS}^{+}$assay, the absorbance of $\mathrm{ABTS}^{+}$could decrease by losing their nitrogen atom [27]. The hydroxy groups found in phenolic contents are able to scavenge DPPH and ABTS radicals [30]. Furthermore, ketonic oxygen, degree of methoxylation, the amount of methyl and methylene within the structure of phenolic compounds indicated the antioxidant potential using DPPH and ABTS assay [31,32]. Catechin consists of numerous hydroxy groups which gave antioxidant effects in vitro and in vivo [33,34]. Furthermore, $p$-coumaric acid is a hydroxyl derivative of cinnamic acid that can directly scavenge the reactive oxygen species (ROS) [35,36]. These phenolic compounds may contribute to the synergistic effect 
on the antioxidant test. Moreover, FRAP assay was evaluated by the reducing ferrous ion $\left(\mathrm{Fe}^{2+}\right)$ from ferric ion $\left(\mathrm{Fe}^{3+}\right)$ [27]. The metal chelating assay was performed by measurement of ferrozine- $\mathrm{Fe}^{2+}$ complex formation. Good metal chelator could have a better competitive binding with ferrous ion than ferrozine in the system [37].

In previous literature, $D$. indusiata found dictyophorines $\mathrm{A}$ and $\mathrm{B}$ as well as dictyoquinazol A, B, and C, which contained ketonic oxygens and hydroxy groups [38]. A previous study also reported that immature and mature $D$. indusiata mushroom comprised high phenolic compounds and contributed to their antioxidant potential [3]. These bioactive substances may affect the scavenging and chelating capacities of the extracts. Free radicals could injure cells and tissues such as membrane lipids, enzymes, and nucleic acids, leading to destructive wound repairing $[39,40]$. Thus, the antioxidant activities of $D$. indusiata extracts might prevent cells and tissues damage resulting in the alleviation of skin wounds.

\subsection{Anti-Inflammatory Activity of Dictyophora indusiata Aqueous Extracts}

2.3.1. Non-Cytotoxic Concentration by the Sulforhodamine B (SRB) Assay on Macrophages

The non-cytotoxic concentration of $D$. indusiata aqueous extracts (PGW, CW, and WW), as evaluated by the SRB assay, was $20 \mu \mathrm{g} / \mathrm{mL}$. This concentration, which provided more than $80 \%$ cell viability [19], was selected for further analyses.

\subsubsection{Anti-Inflammatory Activity}

The inhibitions of NO, IL-1, IL-6 and TNF- $\alpha$ production from 3 types of $D$. indusiata extracts (PGW, CW, and WW) in RAW 264.7 cells, are displayed in Figure 4. For the measurement of nitrite concentration, all extracts significantly decreased nitrite secretion in LPS-induced RAW 264.7 macrophages in a dose-dependent and time-dependent manner $(p<0.05)$. Interestingly, the nitrite concentration of $\mathrm{CW}$ at $20 \mu \mathrm{g} / \mathrm{mL}(0.06 \pm 0.02 \mu \mathrm{mol} / \mathrm{L})$ was significantly lower than of diclofenac sodium $(0.12 \pm 0.02 \mu \mathrm{mol} / \mathrm{L})$ after $72 \mathrm{~h}$ of incubation $(p<0.05)$. The assessment of IL-1 secretion, the results in IL-1 expression of PGW, CW, and WW (at 20 and $0.2 \mu \mathrm{g} / \mathrm{mL}$ ) were significantly de-escalated in LPS-treated RAW 264.7 cells after 24, 48, and $72 \mathrm{~h}(p<0.05)$. For IL-6 production, at the concentration of $20 \mu \mathrm{g} / \mathrm{mL}, \mathrm{PGW}, \mathrm{CW}$, and WW were profoundly inhibited IL-6 secretion comparable with the diclofenac treatment group at 24,48 , and $72 \mathrm{~h}$ tested time. The evaluation of TNF- $\alpha$ secretion, 3 types of extracts at the 20 and $0.2 \mu \mathrm{g} / \mathrm{mL}$ concentration illustrated significant in lowering TNF- $\alpha$ production in LPS-stimulated macrophages after 24,48 , and $72 \mathrm{~h}(p<0.05)$. Especially, $20 \mu \mathrm{g} / \mathrm{mL}$ of PGW and CW depicted complete inhibition of TNF- $\alpha$ secretion at $24 \mathrm{~h}$ of incubation.

This result agreed with a previous study, showing that crude polysaccharide from D. indusiata extracts could reduce inflammatory cytokines (IL-1 $\beta$, IL-6, and TNF- $\alpha$ ) in antibiotic-induced intestinal dysbiosis in mice [41]. Furthermore, ethanolic extracts of D. indusiata could diminish cytokines production in RAW 264.7 cells [42]. Nevertheless, in earlier research, polysaccharide from this mushroom escalated NO, IL-1 $\beta$, IL-6, and TNF- $\alpha$ production [13], activated IL-1 $\beta$, and IL-18 secretion in LPS-induced macrophages [14], and IL-1 $\beta$, IL-6, and IL-18 were enhanced in colitis mice [43]. Recently published studies reported that the bioactive compounds from various sources could regulate the immune system $[39,44-48]$. 


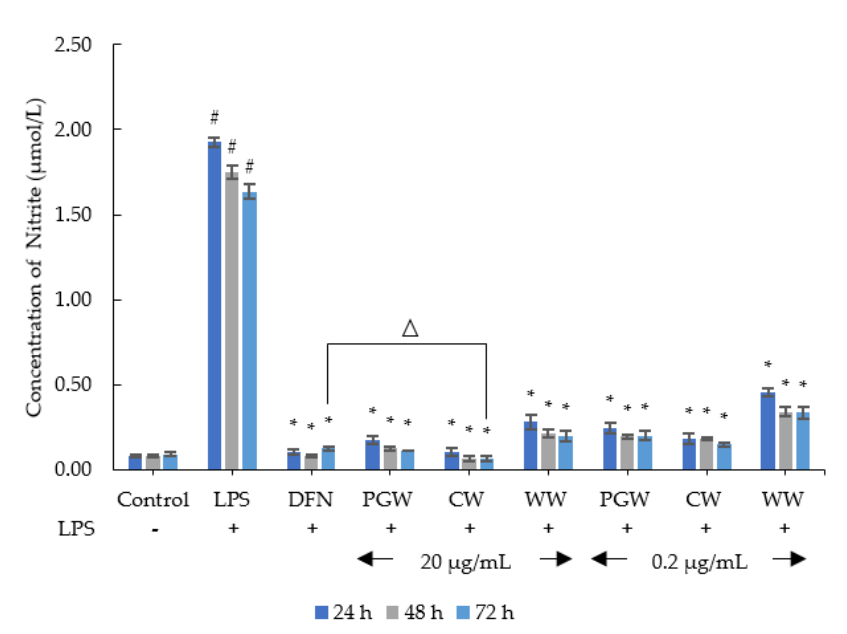

(a)

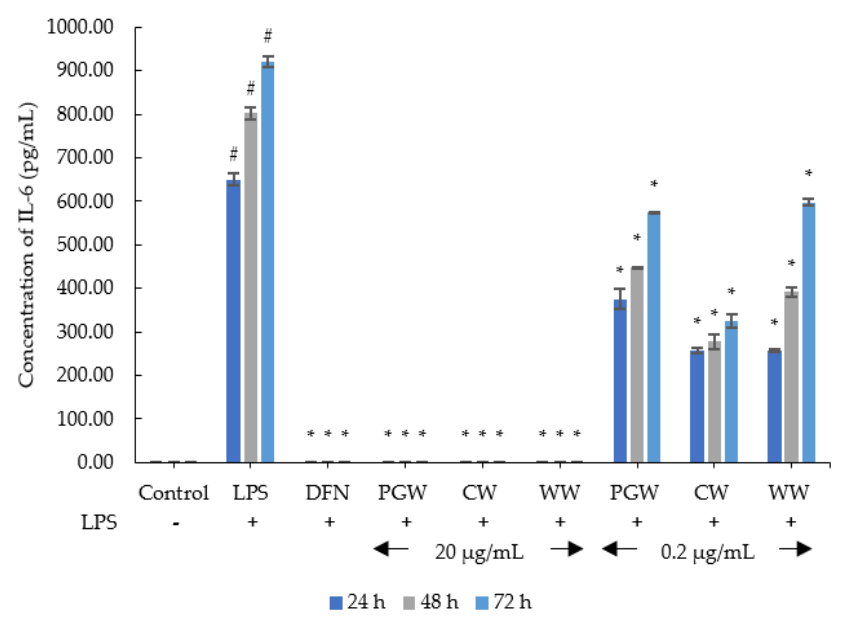

(c)

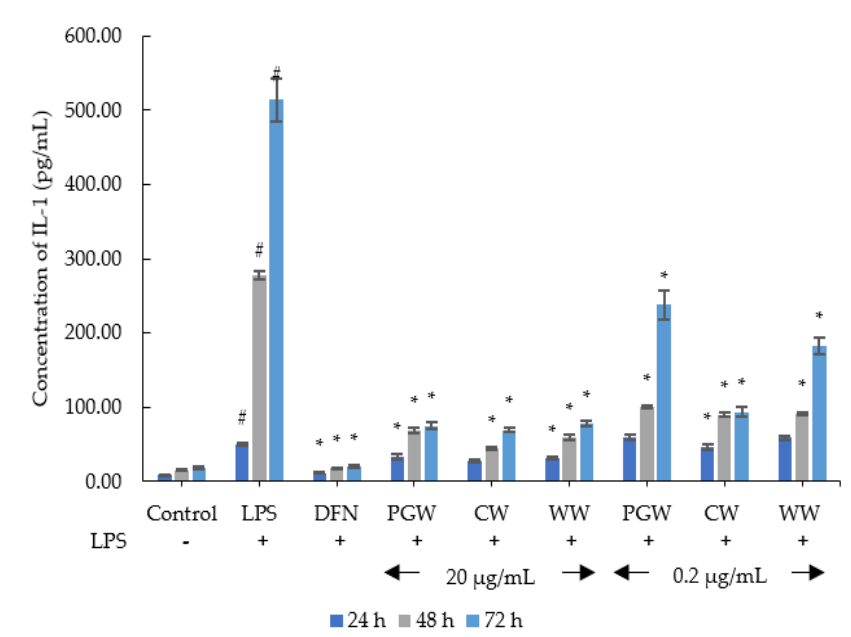

(b)

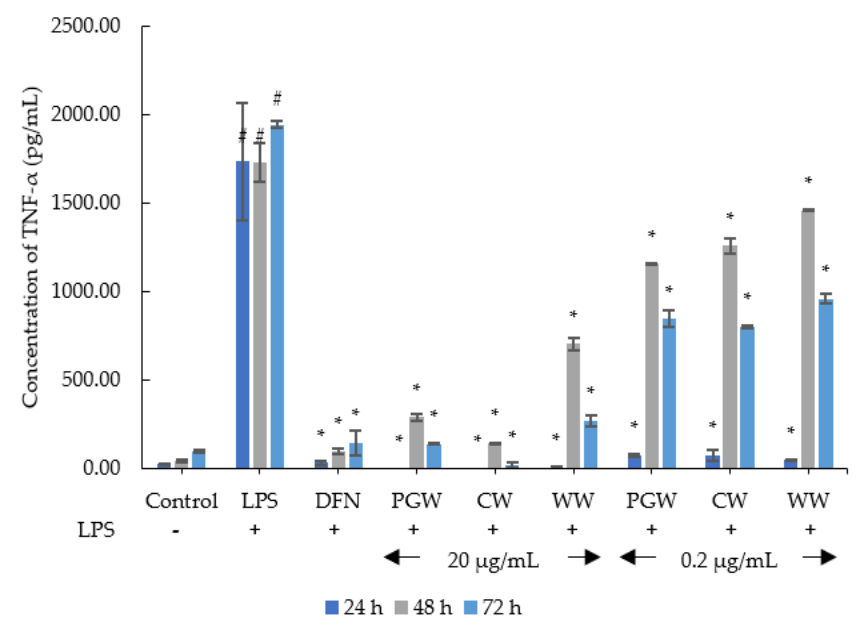

(d)

Figure 4. (a) The nitrite concentration; (b) interleukin-1 $\beta$ (IL-1 $\beta$ ) concentration; (c) interleukin-6 (IL-6) concentration (d) tumour necrosis factor- $\alpha$ (TNF- $\alpha$ ) concentration treated by Dictyophora indusiata aqueous extracts, peel and green mixture (PGW), core (CW), and whole (WW) at each concentration (20 and $0.2 \mu \mathrm{g} / \mathrm{mL}$ ) for $24 \mathrm{~h}, 48 \mathrm{~h}$, and $72 \mathrm{~h}$. DMEM (control), lipopolysaccharides (LPS) (positive control) and diclofenac sodium (DFN) (negative control), respectively. Significant differences are indicated as ${ }^{\#} p<0.05$ (compared to the control), ${ }^{*} p<0.05$ (compared to the positive control), and ${ }^{\Delta} p<0.05$ (compared to the negative control).

IL-1 $\beta$, IL-6, and TNF- $\alpha$ were potent cytokines that dominated in skin wounds [49]. The previous study reported that IL-1, IL-6, and IL-8 significantly upregulated in wound fluids from patients with chronic wounds [50]. Furthermore, non-healing wounds of patients with comorbidity (diabetes and/or cardiovascular disease) found the increasing in cytokines (IL-1 $\beta$, IL-4, IL-6, IL-8, TNF- $\alpha$ ) and growth factors (FGF2, monocyte chemoattractant protein-1 (MCP-1), macrophage inflammatory protein-1 $\alpha$ (MIP-1 $\alpha)$, VEGF-A, and PDGF-BB) levels [51]. So, excessive secretion of cytokines would interfere normal healing process. Moreover, these inflammatory cytokines also caused cutaneous inflammation such as hidradenitis suppurativa [52,53]. MMP-1 and TNF- $\alpha$ contributed to comedones and papules in acne lesions [54]. In addition, Propionibacterium acnes that colonized in the pilosebaceous unit of acne skin can induce the expression of protease activated receptors (PARs), TLRs, TNF- $\alpha$, IL-8, IL12, IL-1, MMPs, interferon- $\gamma$ (IFN- $\gamma$ ), and granulocyte-macrophage colony-stimulating factor (GM-CSF) $[55,56]$. Although, IL-6 took part in the inflammatory phase of skin lesion, but IL- 6 can stimulate fibroblast migration acceleration during the early stage of wound healing $[57,58]$. 
Consequently, the anti-inflammatory potential of $\mathrm{CW}$ could soothe chronic skin inflammation and wound healing impairment. Similar to Brassica oleracea extract which could suppress not only the levels of TNF- $\alpha$, IFN- $\gamma$, IL-6, MCP-1, but also swelling and erythema in dermatitis induced-mice [59]. This corresponds with Momordica charantia extract can inhibit nuclear factor- $\mathrm{KB}(\mathrm{NF}-\mathrm{KB})$ and mitogen-activated protein kinases (MAPK) activation leading to decrease the cytokine (IL-8, IL-1 $\beta$, and TNF- $\alpha$ ) production in P. acnes-stimulated monocytic cells [60].

\subsection{Wound Healing Activity of Dictyophora indusiata Aqueous Extracts}

2.4.1. Non-Cytotoxic Concentration by the Sulforhodamine B (SRB) Assay on Fibroblasts

The non-cytotoxic concentration of bamboo mushroom aqueous extracts (PGW, CW, and $(\mathrm{WW})$, as determined by the SRB assay, was $1 \mathrm{mg} / \mathrm{mL}$ This concentration, which provided more than $80 \%$ cell viability [19], was selected for MMP-2 inhibitory analysis.

\subsubsection{Gelatinolytic Activity (Zymography) of MMP-2 Inhibition}

The D. indusiata aqueous extracts (PGW, CW, and WW) and L-ascorbic acid standard showed the inhibitory effects of the gelatinolytic activity on MMP-2 expression, are illustrated in Figure 5. PGW presented the highest MMP-2 inhibition of $59.63 \pm 8.31 \%$, followed by CW $(41.33 \pm 9.44 \%)$ and WW $(16.33 \pm 2.91 \%)$, respectively. The L-ascorbic acid illustrated the inhibitory effect of $50.65 \pm 2.53 \%$ while concanavalin A exhibited stimulation of gelatinolytic activity as $-52.46 \pm 2.53 \%$. Interestingly, MMP- 2 inhibitory abilities of PGW and CW indicated no significant difference to L-ascorbic acid. Our previous study of bamboo mushroom ethanolic extracts was also reported their MMP-2 inhibitory activity [42].

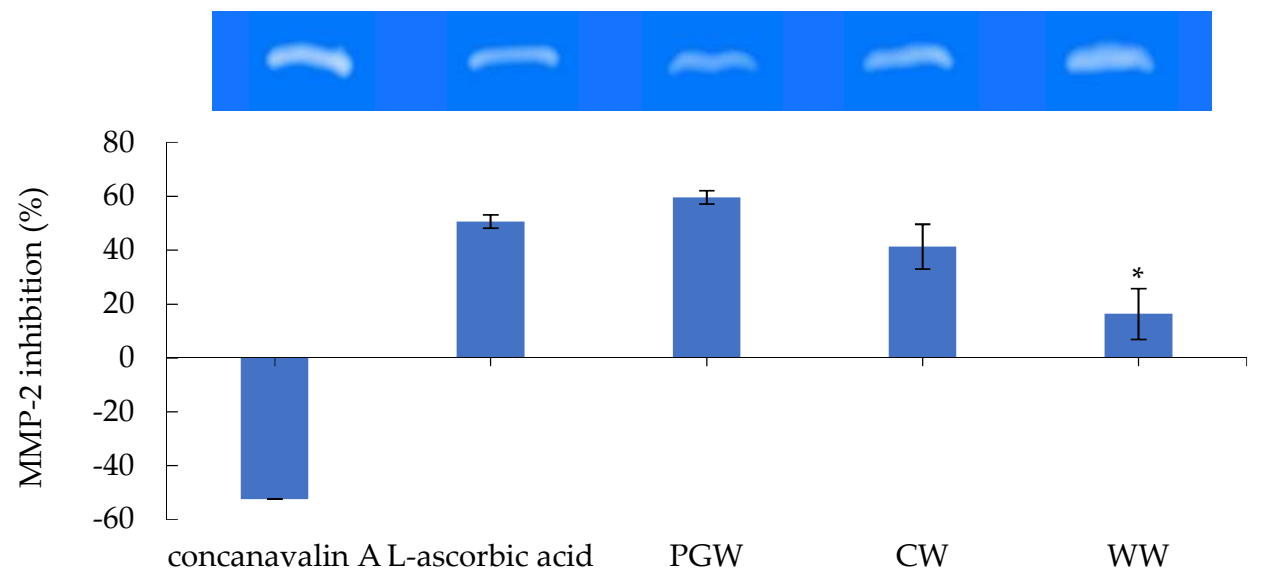

(a)

(b)

Figure 5. (a) Zymograms; (b) the percentages of matrix metalloproteinase 2 (MMP-2) inhibition. The comparison of the gelatinolytic activity of MMP-2 inhibition on human skin fibroblasts between aqueous extracts of Dictyophora indusiata at $1 \mathrm{mg} / \mathrm{mL}$, L-ascorbic acid (positive control), and concanavalin A (negative control), peel and green mixture (PGW), core $(\mathrm{CW})$, whole $(\mathrm{WW})$. Significant differences are indicated as * $p<0.05$ (compared to the positive control).

Pro-MMP-2, MMP-2, MMP-8, and MMP-9 were persistently elevated in wounds from diabetic patients and caused an imbalance of MMP and TIMP-2, leading to healing failure [61]. Additionally, higher MMP-2 mRNA levels in the wound corresponded with IFN- $\gamma$ defection [62]. Furthermore, the excessive production of MMPs is associated with scar formation. The previous literature showed that the levels of type 1 collagen, MMP- 1 , MMP-2, and TIMP-1 in keloid fibroblasts was produced higher than those of normal dermal fibroblasts [63]. Similarly, MMP-2 expression was profoundly greater raised in hypertrophic scars and keloids than non-scarred tissue of patients [64]. Pyoderma gangrenosum, sweet's syndrome, and hidradenitis suppurativa are chronic inflammatory skin diseases that surged not only cytokine expression (such as IL-1 $\beta$, IL-17, IL-23, TNF- $\alpha$ ), but also MMP-2, and 
MMP-9 over-production [65-67]. Furthermore, P. acnes influenced rising TNF- $\alpha$, pro-MMP2 mRNA and protein expression, which caused acne skin [68].

MMP production is related to elastin fibre fragmentation. The secretion of MMPs amplified the matrix remodelling process in hidradenitis suppurativa [66]. Especially, MMP-2 co-localized with keratinocytes, fibroblasts and macrophages cells in the dermis, sweat glands, hair follicles, and sinus tracts [69]. In addition, the reduction of MMP-2 expression could restore collagen types I and III that resulted in accelerating healing in wounds [22]. Interestingly, many medical plants can effectively activate the process of collagen biosynthesis [70,71]. Accordingly, the MMP-2 inhibitory capability of mushroom extracts may interrupt inflammatory skin problems and scar formation. However, the elevation of MMP-2 activity has a positive effect on degrading ECM in the initial state of the wound healing process which gave a benefit for the skin lesion [72].

Among all extracts, $\mathrm{CW}$ could give antioxidant potential and inhibit the production of inflammatory cytokines and MMP-2, which was comparable to the standard. Thus, it was responsible for pharmaceutical and cosmeceutical application as a wound healing product.

\section{Materials and Methods}

\subsection{Materials}

A sample of D. indusiata (Chinese species) in the form of a peach-shaped fruiting body was collected from Maerim's bamboo mushroom farm, Chiang Mai, Thailand, in August 2020. Herbarium voucher specimens of D. indusiata sample (PNPRDU63032) was deposited in the Pharmaceutical and Natural Products Research and Development Unit (PNPRDU), Chiang Mai University, Chiang Mai, Thailand. The D. indusiata aqueous extracts were extracted and obtained from PNPRDU, Chiang Mai University, Chiang Mai, Thailand. The extracts of $D$. indusiata were divided into 3 types: peel and green mixture (PGW), core (CW), and whole mushroom (WW). The extraction method follows a patent pending process. The normal human fibroblasts immortalized by hTRT (OUMS-36T-2) was purchased from JCRB Cell Bank (Osaka, Japan) and RAW 264.7 (Mus musculus, mouse, macrophage) was provided by Assist. Prof. Korawinwich Boonpisuttinan (RMUTT, Thailand). Trypsin, Dulbecco's Modified Eagle Medium (DMEM), Fetal bovine serum (FBS), penicillin, and streptomycin were obtained from Gibco (Grand Island, NY, USA). Trolox, 2,2-diphenyl-1-picrylhydrazyl (DPPH), 2,2-azino-bis (3-ethylbenzothiazoline-6sulfonic acid) (ABTS) diammonium salt, ferrous sulfate, L-ascorbic acid, concanavalin A, ethylenediaminetetraacetic acid (EDTA), diclofenac sodium, and lipopolysaccharides (LPS) from Escherichia coli O55:B5 were purchased from Sigma Chemical Co. (St. Louis, MO, USA). All other chemical substances were of analytical grade.

\subsection{Identification of Dictyophora indusiata Using Polymerase Chain Reaction (PCR) Based on} Ribosomal DNA Internal Transcribed Spacers (rDNA-ITS)

3.2.1. Defining Specific Primers

The sequences of rDNA in ITS regions of $D$. indusiata were designed using the basic local alignment search tool (BLAST) from the national center for biotechnology information (NCBI) (http:/ / www.ncbi.nlm.nih.gov/blast/blast.cgi, accessed on 14 October 2021).

\subsubsection{DNA Extraction and PCR Reactions}

The dry sample was grinded into the powder and performed DNA extraction using NucleoSpin ${ }^{\circledR}$ Plant II (Macherey-Nagel, Germany), according to the instructions of the manufacturer. The PCR solution with a volume of $20 \mu \mathrm{L}$ contained $4 \mu \mathrm{L}$ of $5 \times$ HOT FIREPol ${ }^{\circledR}$ Blend Master Mix (Solid BioDyne, Estonia), $2 \mu \mathrm{L}$ of $10 \mu \mathrm{mol}$ of primer, and $13 \mu \mathrm{L}$ of distillated water. The PCR reactions were performed as start PCR with 10 min initial denaturation at $95^{\circ} \mathrm{C}, 30$ cycles of $30 \mathrm{~s}$ at $95^{\circ} \mathrm{C}, 30 \mathrm{~s}$ at $59{ }^{\circ} \mathrm{C}$, and $30 \mathrm{~s}$ at $68^{\circ} \mathrm{C}$, followed by a final extension of $5 \mathrm{~min}$ at $68^{\circ} \mathrm{C}$. 


\subsubsection{Sequencing and Phylogenetic Analysis}

The PCR products were determined by $2.2 \%$ agarose gel electrophoresis with $100 \mathrm{bp}$ DNA ladder (Solid BioDyne, Estonia), and RedSafe ${ }^{\mathrm{TM}}$ (iNtRON, Korea). The gels were examined by a gel documentation system (Syngene, USA). PCR products were sequenced by Bio Basic Asia Pacific, Singapore. The sequences were aligned using Chromas, and performed Clustal Omega program for the multiple alignment [73]. Nucleotide sequences were compared using BLAST analysis in GenBank databases, followed by the construction of phylogenetic trees using Molecular Evolutionary Genetics Analysis (MEGA) X [74].

\subsection{Determination of Bioactive Compounds}

\subsubsection{Total Phenolic Content}

The total phenolic contents in the extracts were determined by Folin-Ciocalteu colourimetric method, as previously described [42]. The mushroom extracts $(12.5 \mu \mathrm{L})$, water $(50 \mu \mathrm{L})$, and Folin-Ciocalteu reagent $(12.5 \mu \mathrm{L})$ were added into 96-well plates and incubated for $6 \mathrm{~min}$. After that, the mixture was neutralized by $10 \% \mathrm{w} / \mathrm{v}$ saturated sodium bicarbonate solution $(125 \mu \mathrm{L})$ and distilled water $(100 \mu \mathrm{L})$ which kept in the darkness at room temperature for $90 \mathrm{~min}$. Gallic acid in different concentrations $(20-800 \mu \mathrm{g} / \mathrm{mL})$ was used as the standard phenolic substance. Total phenolic content was expressed as $\mathrm{mg}$ of gallic acid equivalents per $\mathrm{g}$ of dry extract (mg GAE/g extract).

\subsubsection{Total Flavonoid Content}

Total flavonoid contents of the extracts were performed using aluminum chloride colourimetric assay, following the previous study [42]. The extracts $(250 \mu \mathrm{L})$ were mixed with distilled water $(1250 \mu \mathrm{L})$ in test-tube. Then, $5.0 \% \mathrm{NaNO}_{2}$ solution $(75 \mu \mathrm{L})$ was added and incubated at room temperature for $10 \mathrm{~min}$. $\mathrm{AlCl}_{3} \cdot 6 \mathrm{H}_{2} \mathrm{O}(150 \mu \mathrm{L})$ was subsequently added and incubated for another $10 \mathrm{~min}$. The mixture was reacted with $1 \mathrm{M}$ of $\mathrm{NaOH}$ $(500 \mu \mathrm{L})$ and distilled water $(275 \mu \mathrm{L})$ before the absorbance measurement. Different concentrations of catechin $(0.01-0.32 \mathrm{mg} / \mathrm{mL})$ were used in the standard calibration curve for total flavonoid determination. Total flavonoid content was expressed as $\mathrm{mg}$ of catechin equivalents per $\mathrm{g}$ of dry weight of each extract (mg CE/g extract).

\subsubsection{Total Polysaccharide Content}

Total polysaccharide contents of the extracts were measured by Anthrone-Sulfuric acid method, as previous described [42]. The samples $(250 \mu \mathrm{L})$ were reacted with $750 \mu \mathrm{L}$ of Anthrone sulphate solution. The mixture was heated at $37^{\circ} \mathrm{C}$ for $15 \mathrm{~min}$ and then cooled down for another $15 \mathrm{~min}$. D-glucose monohydrate (in the range of $0.1-0.6 \mathrm{mg} / \mathrm{mL}$ ) was used as a standard polysaccharide substance. The results of polysaccharide content were represented as $\mu \mathrm{g}$ of glucose equivalents per g of dry weight of each extract ( $\mu \mathrm{g} \mathrm{GE} / \mathrm{g}$ extract).

3.3.4. Quantitative Analysis of Phenolic and Flavonoid by Liquid Chromatography-Electrospray Ionization/Mass Spectrometry (LC-ESI/MS)

The extracts $(10 \mathrm{mg})$ were dissolved in ethanol and filtrated through a $0.45 \mu \mathrm{m}$ syringe filter into a vial bottle. The analysis was performed according to the already reported methods with some modifications [47,75] and analyzed using an Agilent 1260 Infinity II series, coupled with an electrospray ion (ESI) quadrupole mass spectrometry 6130 (Agilent Tech., Santa Clara, CA, USA). Reverse-phase column chromatography was performed using the Restek Ultra C18 column $(250 \times 4.6 \mathrm{~mm}, 4.6 \mathrm{~mm}, 5 \mu \mathrm{m})$ (Restek, Bellefonte, PA, USA). The column was maintained at $30^{\circ} \mathrm{C}$. The gradient elution was carried out using the $5 \%$ formic acid as a solvent $\mathrm{A}$ and acetonitrile: $\mathrm{H}_{2} \mathrm{O}$ : formic acid (85: 10: 5) as a solvent $\mathrm{B}$ with a linear gradian elution as $0-8 \mathrm{~min}, 80 \% \mathrm{~A} ; 8-24 \mathrm{~min}$, decreased $\mathrm{A}$ to $25 \% ; 24-28 \mathrm{~min}$, $25 \% \mathrm{~A} ; 28-34 \mathrm{~min}$, increased A to $70 \% ; 34-36 \mathrm{~min}$, increased A to $80 \% ; 36-45 \mathrm{~min}, 80 \%$ A. The injection volume for all samples was $5 \mu \mathrm{L}$ which was monitored at the flow rate of $0.5 \mathrm{~mL} \mathrm{ml} / \mathrm{min}$. The MS was operated in the negative selected ion monitoring (SIM) as the following condition: dying gas (N2) flow, $12 \mathrm{~L} / \mathrm{min}$; dying gas temperature, $350{ }^{\circ} \mathrm{C}$; 
nebulizer pressure, 60 psi; capillary voltage, $3000 \mathrm{~V}$; fragmentor voltage, $70 \mathrm{~V}$; and the full scan spectra from 100 to $1200 \mathrm{~m} / \mathrm{z}$ with $250 \mathrm{~ms} /$ spectrum. The spectra were processed using Open Lab software (Agilent Tech., Santa Clara, CA, USA).

\subsection{Antioxidant Assay of Dictyophora indusiata Aqueous Extracts}

\subsubsection{DPPH Radical Scavenging Activity}

The DPPH radical scavenging activity of PGW, CW, and WW was determined using DPPH by following the modified method [76]. The extracts were diluted with distilled water in the range of $0.0032-10 \mathrm{mg} / \mathrm{mL}$. L-ascorbic acid was used as the positive control. The percentages of the DPPH scavenging activity were calculated by Equation (1), where Abs Control is the absorbance of DPPH solution, and Abs sample is the absorbance of DPPH radicals reacted with extracts or standard:

$$
\text { DPPH scavenging activity }(\%)=\frac{\left(\operatorname{Abs}_{\text {Control }}-\mathrm{Abs}_{\text {Sample }}\right)}{\mathrm{Abs}_{\text {Control }}} \times 100
$$

The linear relationship between the concentration of samples and the percentages of DPPH radical scavenging activity was plotted and calculated to the concentration providing $50 \%$ scavenging activity $\left(\mathrm{SC}_{50}\right)(\mathrm{mg} / \mathrm{mL})$.

\subsection{2. $\mathrm{ABTS}^{+}$Scavenging Activity}

The $\mathrm{ABTS}^{+}$assay was determined by the previous method [76]. Briefly, $\mathrm{ABTS}^{+}$solution was diluted with methanol to reach the absorbance of $0.68-0.72$ at $734 \mathrm{~nm}$. Then, $290 \mu \mathrm{L}$ of $\mathrm{ABTS}^{+}$solution reacted with $10 \mu \mathrm{L}$ of different concentrations of the extracts (in the range of $0.625-30 \mathrm{mg} / \mathrm{mL}$ ) for $10 \mathrm{~min}$. The inhibitory concentration of samples was determined from a standard curve of Trolox. Then, the linear relationship between the concentration and the absorbance of samples was evaluated to obtain the $\mathrm{SC}_{50}(\mathrm{mg} / \mathrm{mL})$.

\subsubsection{Metal Chelating Activity}

The metal chelation by the extracts was determined using the inhibition of ferrozineferrous ion $\left(\mathrm{Fe}^{2+}\right)$ complex formation, as previous described [42]. EDTA standard was used as the positive control. The percentages of chelating activity were calculated by Equation (2), Abs Control is the absorbance of ferrozine- $\mathrm{Fe}^{2+}$ complex, and Abs sample is the absorbance of the complex reacted with extracts or standard:

$$
\text { Chelating } \operatorname{activity}(\%)=\frac{\left(\operatorname{Abs}_{\mathrm{Control}}-\mathrm{Abs}_{\text {Sample }}\right)}{\mathrm{Abs}_{\mathrm{Control}}} \times 100
$$

The linear relationship between the concentration of samples and the percentages of chelating activity was plotted and calculated to the concentration providing $90 \%$ chelating activity $\left(\mathrm{MC}_{90}\right)(\mathrm{mg} / \mathrm{mL})$.

\subsubsection{Ferric Reducing Antioxidant Power (FRAP) Assay}

The reducing power of extracts from $D$. indusiata was determined by FRAP assay, using the reported method [42]. FRAP reagent was prepared by $300 \mathrm{mmol} / \mathrm{L}$ acetate buffer, $20 \mathrm{mmol} / \mathrm{L}$ ferric chloride, and $10 \mathrm{mmol} / \mathrm{L} \mathrm{2,4,6-tripyridyl-5-triazine} \mathrm{in} \mathrm{the} \mathrm{ratio}$ 10:1:1 (v:v:v). Then, $280 \mu \mathrm{L}$ of FRAP reagent reacted with the extracts (in the range of $0.625-30 \mathrm{mg} / \mathrm{mL}$ ) for $30 \mathrm{~min}$ at room temperature. Antioxidant potential of the extracts was calculated from the standard curve of ferrous sulfate. The result was represented as $\mu \mathrm{M} \mathrm{Fe}^{2+} / \mathrm{g}$ extract. 


\subsection{Anti-inflammatory Activity of Dictyophora indusiata Aqueous Extracts}

\subsubsection{Cell Culture}

The RAW 264.7 macrophages were cultured in DMEM, supplemented with $10 \%(v / v)$ FBS, D-glucose $(4500 \mathrm{mg} / \mathrm{L})$, penicillin $(100 \mathrm{U} / \mathrm{mL})$ and streptomycin $(100 \mathrm{mg} / \mathrm{mL})$. The cells were incubated in a temperature-controlled and humidified incubator (CCL-050B-8, Esco ${ }^{\circledR}$, Singapore) with $5 \% \mathrm{CO}_{2}$ at $37^{\circ} \mathrm{C}$ until the subcultures reached a confluence of $80 \%$.

3.5.2. Determination of Non-Cytotoxic Concentration by the Sulforhodamine B (SRB) Assay on Macrophages

The samples were tested for non-cytotoxic concentration on the RAW 264.7 macrophages by the SRB assay, the method was used with some modifications [77]. The cells $\left(1 \times 10^{5}\right.$ cells $\left./ \mathrm{mL}\right)$ were plated in 96-well plates and were incubated for $24 \mathrm{~h}$. The cells were exposed to diclofenac sodium and the extracts (in the range of $0.0001-1 \mathrm{mg} / \mathrm{mL}$ ) for another 24,48 , and $72 \mathrm{~h}$, respectively. Then, the adherent cells were fixed in situ, washed, and dyed with SRB. The bound dye was solubilized, and the absorbance was measured at $515 \mathrm{~nm}$. The percentages of cell viability were calculated by Equation (3), where Abs denotes absorbance:

$$
\text { Cell viability }(\%)=\frac{\left(\mathrm{Abs}_{\text {Sample }}-\mathrm{Abs}_{\text {blank }}\right)}{\left(\mathrm{Abs}_{\text {Control }}-\mathrm{Abs}_{\text {blank }}\right)} \times 100
$$

\subsubsection{Determination of NO, IL-1, IL-6, and TNF- $\alpha$ Levels}

NO, IL-1, IL-6 and TNF- $\alpha$ Levels were determined as previously described with slight modification [78]. The RAW 264.7 cells $\left(1 \times 10^{5}\right.$ cells $\left./ \mathrm{mL}\right)$ were cultured in 96-well plates for $24 \mathrm{~h}$ and treated with the samples (PGW, CW, and WW), and diclofenac sodium standard for $1 \mathrm{~h}$. The treated cells were induced by $1 \mu \mathrm{g} / \mathrm{mL}$ of LPS for 24,48 , and $72 \mathrm{~h}$, respectively. LPS was used as the positive control and diclofenac sodium was used as the negative control. After incubation, the supernatants were collected and determined for nitrite by using the Griess reagent kit (Thermo Fisher Scientific, Waltham, MA, USA), for IL-1 $\beta$, IL-6, and TNF- $\alpha$ levels using ELISA kits (PEPROTECH, USA), according to the instructions of the manufacturer.

\subsection{Collagen Stimulating Activity of Dictyophora indusiata Aqueous Extracts}

\subsubsection{Cell Culture}

The $h T R T$ fibroblasts were cultured in DMEM, supplemented with $10 \%(v / v)$ FBS, penicillin $(100 \mathrm{U} / \mathrm{mL})$ and streptomycin $(100 \mathrm{mg} / \mathrm{mL})$. The cells were incubated in a temperature-controlled and humidified incubator (CCL-050B-8, Esco ${ }^{\circledR}$, Singapore) with $5 \%$ $\mathrm{CO}_{2}$ at $37^{\circ} \mathrm{C}$ until the subcultures reached a confluence of $80 \%$.

3.6.2. Determination of Non-Cytotoxic Concentration by the Sulforhodamine B (SRB) Assay on Fibroblasts

The samples were tested for non-cytotoxic concentration on the $h T R T$ fibroblasts by the SRB assay, the method was used with some modifications [77]. The cells $\left(1 \times 10^{5}\right.$ cells $\left./ \mathrm{mL}\right)$ were plated in 96-well plates and were incubated for $24 \mathrm{~h}$. The fibroblasts were treated with different concentrations of L-ascorbic acid, concanavalin A, and the extracts (in the range of $0.0001-1 \mathrm{mg} / \mathrm{mL}$ ) for another $24 \mathrm{~h}$. After that, the adherent cells were fixed in situ, washed, and dyed with SRB. The bound dye was solubilized, and the absorbance was measured at $515 \mathrm{~nm}$.

\subsubsection{Gelatinolytic Activity (Zymography) of MMP-2 Inhibition}

MMP-2 level was determined according to the previous method [76]. The fibroblasts $\left(5 \times 10^{5}\right.$ cells $\left./ \mathrm{mL}\right)$ were cultured in 6-well plates for $24 \mathrm{~h}$ and maintained in the culture medium without FBS for another $24 \mathrm{~h}$. Then the cells were treated with the samples (PGW, $\mathrm{CW}$, and WW), concanavalin A (negative control) and L-ascorbic acid (positive control) standard, respectively, and incubated for $48 \mathrm{~h}$. The cultured supernatants were collected 
and tested on $10 \%$ SDS-PAGE gels containing $1 \mathrm{mg} / \mathrm{mL}$ of gelatin. The gels were stained with $0.5 \%$ Coomassie Brilliant Blue G-250, scanned by a gel documentation system (Gel Doc $^{\mathrm{TM}}$ EZ Gel, Bio-Rad Laboratories, Hercules, CA, USA) and analysed using the Image $\mathrm{Lab}^{\mathrm{TM}}$ software 5.1 (Bio-Rad Laboratories, USA). The volume (intensity) multiplied by the number of pixels of the bands on the gel was determined as the relative MMP-2 content (intensity unit). The percentages of MMP-2 inhibition relative to the control (the untreated systems) were calculated by Equation (4):

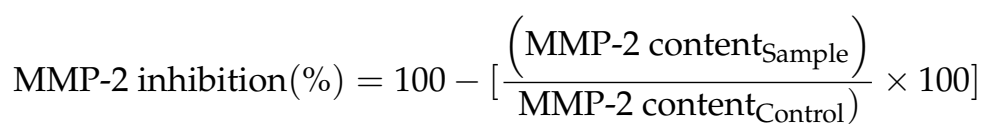

\subsection{Statistical Analysis}

All experiments were operated in at least triplicate for each test. Data was expressed as means \pm standard deviation (SD). One-way ANOVA, followed by LSD's post hoc test was used to analyse the significant differences using SPSS 23.0 software (SPSS Inc., Chicago, IL, USA). A value of $p<0.05$ was considered statistically significant.

\section{Conclusions}

Since there is no publication of the in vitro wound healing effect of immature (egg) bamboo mushroom extracts, the anti-inflammatory and collagen stimulating (MMP-2 inhibition) activities for the wound healing were carried out in this study. The aqueous extracts from the immature stage of core $D$. indusiata mushroom showed the considerable wound healing effect not only with the highest antioxidant activity, the comparable antiinflammation via the reduction of cytokines (NO, IL-1, IL-6, and TNF- $\alpha$ ) secretion from LPS-induced macrophage cells to the standard diclofenac, but also the promising MMP-2 inhibition through the determination of gelatinolytic activity on fibroblasts cells which were responsible for inflammation, cell proliferation, and tissue remodelling stages in the wound healing process, respectively. Over-production of inflammatory cytokines and MMP-2 lead to wound healing impairment, chronic skin inflammatory diseases, and scar formation. Therefore, CW which provided the high content of catechin, other polyphenolic compounds, and the effective anti-inflammation and MMP-2 inhibition activity could have the promising in vivo wound healing effect could be a candidate to develop as pharmaceutical and/or cosmeceutical wound healing active ingredients. Hence, the in vivo study of CW extract should be further investigated in animal and volunteers with wound injury for the honorable result. The animal and human ethical approval are currently on the application process.

Author Contributions: Conceptualization, W.R. and K.S.; methodology, W.R., K.S., J.T., S.M., A.W. and P.J.; software, C.C., S.R.S. and K.J.; validation, C.K. and C.A.; formal analysis, W.R. and P.L.; investigation, C.K. and P.L.; resources, K.S.; visualization, P.L.; Y.N.; data curation, C.K, T.C.; writingoriginal draft preparation, W.R., T.C. and P.L.; writing-review and editing, W.R., F.J.B., H.B., P.L., Y.P. and P.R.; supervision, W.R.; project administration, W.R.; funding acquisition, W.R. All authors have read and agreed to the published version of the manuscript.

Funding: This research received no external funding.

Institutional Review Board Statement: Not applicable.

Informed Consent Statement: Not applicable.

Acknowledgments: The authors gratefully acknowledge the Chiang Mai University, Chiang Mai, Thailand, and CMU presidential scholarship. The current research was partially supported by Chiang Mai University.

Conflicts of Interest: The authors declare no conflict of interest. 


\section{References}

1. Taofiq, O.; González-Paramás, A.M.; Martins, A.; Barreiro, M.F.; Ferreira, I.C. Mushrooms extracts and compounds in cosmetics, cosmeceuticals and nutricosmetics-A review. Ind. Crop. Prod. 2016, 90, 38-48. [CrossRef]

2. Wu, Y.; Choi, M.-H.; Li, J.; Yang, H.; Shin, H.-J. Mushroom cosmetics: The present and future. Cosmetics 2016, 3, 22. [CrossRef]

3. Srisuk, N.; Jirasatid, N. Characteristics co-encapsulation of Lactobacillus acidophilus with Dictyophora indusiata. Curr. Res. Nutr. Food Sci. 2020, 8, 1013. [CrossRef]

4. Burapapadh, K.; Changsan, N.; Sinsuebpol, C.; Saokham, P. An evaluation of Dictyophora indusiata mucilage as a binder in tablet formulations. Key Eng. Mater. 2021, 901, 22-27. [CrossRef]

5. Habtemariam, S. The chemistry, pharmacology and therapeutic potential of the edible mushroom Dictyophora indusiata (Vent ex. Pers.) Fischer (Synn. Phallus indusiatus). Biomedicines 2019, 7, 98. [CrossRef]

6. Wang, J.; Wen, X.; Zhang, Y.; Zou, P.; Cheng, L.; Gan, R.; Li, X.; Liu, D.; Geng, F. Quantitative proteomic and metabolomic analysis of Dictyophora indusiata fruiting bodies during post-harvest morphological development. Food Chem. 2021, 339, 127884. [CrossRef]

7. Wang, W.; Song, X.; Zhang, J.; Li, H.; Liu, M.; Gao, Z.; Wang, X.; Jia, L. Antioxidation, hepatic-and renal-protection of waterextractable polysaccharides by Dictyophora indusiata on obese mice. Int. J. Biol. Macromol. 2019, 134, 290-301. [CrossRef]

8. Talebi, M.; Kakouri, E.; Talebi, M.; Tarantilis, P.A.; Farkhondeh, T.; İlgün, S.; Pourbagher-Shahri, A.M.; Samarghandian, S. Nutraceuticals-based therapeutic approach: Recent advances to combat pathogenesis of Alzheimer's disease. Expert Rev. Neurother. 2021, 21, 625-642. [CrossRef]

9. Oyetayo, V.; Dong, C.-H.; Yao, Y.-J. Antioxidant and antimicrobial properties of aqueous extract from Dictyophora indusiata. Open Mycol. J. 2009, 3, 20-26. [CrossRef]

10. Sharma, V.K.; Choi, J.; Sharma, N.; Choi, M.; Seo, S.Y. In vitro anti-tyrosinase activity of 5-(hydroxymethyl)-2-furfural isolated from Dictyophora indusiata. Phytother. Res. 2004, 18, 841-844. [CrossRef]

11. Hua, Y.; Yang, B.; Tang, J.; Ma, Z.; Gao, Q.; Zhao, M. Structural analysis of water-soluble polysaccharides in the fruiting body of Dictyophora indusiata and their in vivo antioxidant activities. Carbohydr. Polym. 2012, 87, 343-347. [CrossRef]

12. Liao, W.; Luo, Z.; Liu, D.; Ning, Z.; Yang, J.; Ren, J. Structure characterization of a novel polysaccharide from Dictyophora indusiata and its macrophage immunomodulatory activities. J. Agric. Food Chem. 2015, 63, 535-544. [CrossRef]

13. Deng, C.; Shang, J.; Fu, H.; Chen, J.; Liu, H.; Chen, J. Mechanism of the immunostimulatory activity by a polysaccharide from Dictyophora indusiata. Int. J. Biol. Macromol. 2016, 91, 752-759. [CrossRef]

14. Wang, Y.; Lai, L.; Teng, L.; Li, Y.; Cheng, J.; Chen, J.; Deng, C. Mechanism of the anti-inflammatory activity by a polysaccharide from Dictyophora indusiata in lipopolysaccharide-stimulated macrophages. Int. J. Biol. Macromol. 2019, 126, 1158-1166. [CrossRef]

15. Shih, B.; Garside, E.; McGrouther, D.A.; Bayat, A. Molecular dissection of abnormal wound healing processes resulting in keloid disease. Wound Repair Regen. 2010, 18, 139-153. [CrossRef]

16. Schultz, G.S.; Sibbald, R.G.; Falanga, V.; Ayello, E.A.; Dowsett, C.; Harding, K.; Romanelli, M.; Stacey, M.C.; Teot, L.; Vanscheidt, W Wound bed preparation: A systematic approach to wound management. Wound Repair Regen. 2003, 11, S1-S28. [CrossRef] [PubMed]

17. Enoch, S.; Leaper, D.J. Basic science of wound healing. Surgery 2005, 23, 37-42.

18. Buranasukhon, W.; Athikomkulchai, S.; Tadtong, S.; Chittasupho, C. Wound healing activity of Pluchea indica leaf extract in oral mucosal cell line and oral spray formulation containing nanoparticles of the extract. Pharm. Biol. 2017, 55, 1767-1774. [CrossRef]

19. Ruksiriwanich, W.; Khantham, C.; Linsaenkart, P.; Jantrawut, P.; Rajchasom, S. Optimization of placenta extraction for wound healing activity. Chiang Mai J. Sci. 2019, 46, 946-959.

20. Menon, S.N.; Flegg, J.A.; McCue, S.W.; Schugart, R.C.; Dawson, R.A.; McElwain, D.S. Modelling the interaction of keratinocytes and fibroblasts during normal and abnormal wound healing processes. Proc. R. Soc. B Biol. Sci. 2012, 279, 3329-3338. [CrossRef] [PubMed]

21. Dong, C.; Virtucio, C.; Zemska, O.; Baltazar, G.; Zhou, Y.; Baia, D.; Jones-Iatauro, S.; Sexton, H.; Martin, S.; Dee, J. Treatment of skin inflammation with benzoxaborole phosphodiesterase inhibitors: Selectivity, cellular activity, and effect on cytokines associated with skin inflammation and skin architecture changes. J. Pharmacol. Exp. Ther. 2016, 358, 413-422. [CrossRef] [PubMed]

22. Aparecida Da Silva, A.; Leal-Junior, E.C.P.; Alves, A.C.A.; Rambo, C.S.; Dos Santos, S.A.; Vieira, R.P.; De Carvalho, P.D.T.C. Woundhealing effects of low-level laser therapy in diabetic rats involve the modulation of MMP-2 and MMP-9 and the redistribution of collagen types I and III. J. Cosmet. Laser Ther. 2013, 15, 210-216. [CrossRef]

23. Dictyophora indusiata f. lutea 18S Ribosomal RNA Gene, Partial Sequence; Internal Transcribed Spacer 1, 5.8S Ribosomal RNA Gene, and Internal Transcribed Spacer 2, Complete Sequence; and 28S Ribosomal RNA Gene, Partial Sequence. Available online: https: / / www.ncbi.nlm.nih.gov / nuccore/329568060 (accessed on 14 October 2021).

24. Dictyophora indusiata Strain ASI 32001 Internal Transcribed Spacer 1, Partial Sequence; 5.8S Ribosomal RNA Gene, Complete Sequence; and Internal Transcribed Spacer 2, Partial Sequence. Available online: https://www.ncbi.nlm.nih.gov/nuccore/3056 96830 (accessed on 14 October 2021).

25. Ruamrungsri, N.; Siengdee, P.; Sringarm, K.; Chomdej, S.; Ongchai, S.; Nganvongpanit, K. In vitro cytotoxic screening of 31 crude extracts of Thai herbs on a chondrosarcoma cell line and primary chondrocytes and apoptotic effects of selected extracts. In Vitro Cell Dev. Biol. Anim. 2016, 52, 434-444. [CrossRef] [PubMed] 
26. Arjin, C.; Pringproa, K.; Hongsibsong, S.; Ruksiriwanich, W.; Seel-Audom, M.; Mekchay, S.; Sringarm, K. In vitro screening antiviral activity of Thai medicinal plants against porcine reproductive and respiratory syndrome virus. BMC Vet. Res. 2020, 16, 102. [CrossRef]

27. Ozcan, T.; Sahin, S.; Akpinar-Bayizit, A.; Yilmaz-Ersan, L. Assessment of antioxidant capacity by method comparison and amino acid characterisation in buffalo milk kefir. Int. J. Dairy Technol. 2019, 72, 65-73. [CrossRef]

28. Surin, S.; You, S.; Seesuriyachan, P.; Muangrat, R.; Wangtueai, S.; Jambrak, A.R.; Phongthai, S.; Jantanasakulwong, K.; Chaiyaso, T.; Phimolsiripol, Y. Optimization of ultrasonic-assisted extraction of polysaccharides from purple glutinous rice bran (Oryza sativa L.) and their antioxidant activities. Sci. Rep. 2020, 10, 10410. [CrossRef] [PubMed]

29. Manosroi, A.; Ruksiriwanich, W.; Abe, M.; Sakai, H.; Aburai, K.; Manosroi, W.; Manosroi, J. Physico-chemical properties of cationic niosomes loaded with fraction of rice (Oryza sativa) bran extract. J. Nanosci. Nanotechnol. 2012, 12, 7339-7345. [CrossRef]

30. Sangta, J.; Wongkaew, M.; Tangpao, T.; Withee, P.; Haituk, S.; Arjin, C.; Sringarm, K.; Hongsibsong, S.; Sutan, K.; Pusadee, T. Recovery of polyphenolic fraction from arabica coffee pulp and its antifungal applications. Plants 2021, 10, 1422. [CrossRef]

31. Mitra, I.; Saha, A.; Roy, K. Exploring quantitative structure-activity relationship studies of antioxidant phenolic compounds obtained from traditional Chinese medicinal plants. Mol. Simul. 2010, 36, 1067-1079. [CrossRef]

32. Chaiwong, N.; Leelapornpisid, P.; Jantanasakulwong, K.; Rachtanapun, P.; Seesuriyachan, P.; Sakdatorn, V.; Leksawasdi, N.; Phimolsiripol, Y. Antioxidant and moisturizing properties of carboxymethyl chitosan with different molecular weights. Polymers 2020, 12, 1445. [CrossRef]

33. Zanwar, A.A.; Badole, S.L.; Shende, P.S.; Hegde, M.V.; Bodhankar, S.L. Antioxidant role of catechin in health and disease. In Polyphenols in Human Health and Disease; Elsevier: Amsterdam, The Netherlands, 2014; pp. 267-271.

34. Muzolf-Panek, M.; Gliszczyńska-Świgło, A.; Szymusiak, H.; Tyrakowska, B. The influence of stereochemistry on the antioxidant properties of catechin epimers. Eur. Food Res. Technol. 2012, 235, 1001-1009. [CrossRef]

35. Zang, L.-Y.; Cosma, G.; Gardner, H.; Shi, X.; Castranova, V.; Vallyathan, V. Effect of antioxidant protection by $p$-coumaric acid on low-density lipoprotein cholesterol oxidation. Am. J. Physiol. Cell Physiol. 2000, 279, C954-C960. [CrossRef] [PubMed]

36. Kiliç, I.; Yeşiloğlu, Y. Spectroscopic studies on the antioxidant activity of p-coumaric acid. Spectrochim Acta A Mol. Biomol. Spectrosc. 2013, 115, 719-724. [CrossRef] [PubMed]

37. Gulcin, İ.; Buyukokuroglu, M.E.; Kufrevioglu, O.I. Metal chelating and hydrogen peroxide scavenging effects of melatonin. J. Pineal Res. 2003, 34, 278-281. [CrossRef]

38. Phan, C.-W.; David, P.; Sabaratnam, V. Edible and medicinal mushrooms: Emerging brain food for the mitigation of neurodegenerative diseases. J. Med. Food 2017, 20,1-10. [CrossRef]

39. Surin, S.; Surayot, U.; Seesuriyachan, P.; You, S.; Phimolsiripol, Y. Antioxidant and immunomodulatory activities of sulphated polysaccharides from purple glutinous rice bran (Oryza sativa L.). Int. J. Food Sci. Technol. 2018, 53, 994-1004. [CrossRef]

40. Leelapornpisid, P.; Chansakaow, S.; Na-Boonlong, S.; Jantrawut, P. Development of cream containing nanostructured lipid carriers loaded marigold (tagetes erecta linn) flowers extract for anti-wrinkles application. Int. J. Pharm. Pharm. Sci. 2014, 6, 313-314.

41. Kanwal, S.; Joseph, T.P.; Owusu, L.; Xiaomeng, R.; Meiqi, L.; Yi, X. A polysaccharide isolated from Dictyophora indusiata promotes recovery from antibiotic-driven intestinal dysbiosis and improves gut epithelial barrier function in a mouse model. Nutrients 2018, 10, 1003. [CrossRef] [PubMed]

42. Ruksiriwanich, W.; Khantham, C.; Linsaenkart, P.; Chaitep, T.; Rachtanapun, P.; Jantanasakulwong, K.; Phimolsiripol, Y.; Jambrak, A.R.; Nazir, Y.; Yooin, W. Anti-inflammation of bioactive compounds from ethanolic extracts of edible bamboo mushroom (Dictyophora indusiata) as functional health promoting food ingredients. Int. J. Food Sci. Technol. 2021, 57, 110-122. [CrossRef]

43. Wang, Y.; Ji, X.; Yan, M.; Chen, X.; Kang, M.; Teng, L.; Wu, X.; Chen, J.; Deng, C. Protective effect and mechanism of polysaccharide from Dictyophora indusiata on dextran sodium sulfate-induced colitis in C57BL/6 mice. Int. J. Biol. Macromol. 2019, 140, 973-984. [CrossRef]

44. Chaisuwan, W.; Jantanasakulwong, K.; Wangtueai, S.; Phimolsiripol, Y.; Chaiyaso, T.; Techapun, C.; Phongthai, S.; You, S.; Regenstein, J.M.; Seesuriyachan, P. Microbial exopolysaccharides for immune enhancement: Fermentation, modifications and bioactivities. Food Biosci. 2020, 35, 100564. [CrossRef]

45. Surayot, U.; Wangtueai, S.; You, S.; Palanisamy, S.; Krusong, W.; Brennan, C.S.; Barba, F.J.; Phimolsiripol, Y.; Seesuriyachan, P. Extraction, structural characterisation, and immunomodulatory properties of edible Amanita hemibapha subspecies javanica (Corner and Bas) mucilage polysaccharide as a potential of functional food. J. Fungi 2021, 7, 683. [CrossRef]

46. Surayot, U.; Wangtueai, S.; You, S.; Techapun, C.; Phimolsiripol, Y.; Leksawasdi, N.; Krusong, W.; Barba, F.J.; Seesuriyachan, P. Sulphation and hydrolysis improvements of bioactivities, and immuno-modulatory properties of edible Amanita hemibapha subspecies javanica (Corner and Bas) mucilage polysaccharide as a potential in personalized functional foods. J. Fungi $2021,7,847$. [CrossRef]

47. Arjin, C.; Hongsibsong, S.; Pringproa, K.; Seel-audom, M.; Ruksiriwanich, W.; Sutan, K.; Sommano, S.R.; Sringarm, K. Effect of ethanolic Caesalpinia sappan fraction on in vitro antiviral activity against porcine reproductive and respiratory syndrome virus. Vet. Sci. 2021, 8, 106. [CrossRef]

48. Manosroi, A.; Lohcharoenkal, W.; Ruksiriwanich, W.; Kietthanakorn, B.-O.; Manosroi, W.; Manosroi, J. In vitro immunostimulating activity of the dried sap from fermented thai rice on human and murine neutrophils. Adv. Sci. Lett. 2012, 17, 306-311. [CrossRef] 
49. Grellner, W.; Georg, T.; Wilske, J. Quantitative analysis of proinflammatory cytokines (IL-1 $\beta$, IL-6, TNF- $\alpha$ ) in human skin wounds. Forensic Sci. Int. 2000, 113, 251-264. [CrossRef]

50. Wiegand, C.; Schönfelder, U.; Abel, M.; Ruth, P.; Kaatz, M.; Hipler, U.-C. Protease and pro-inflammatory cytokine concentrations are elevated in chronic compared to acute wounds and can be modulated by collagen type I in vitro. Arch. Dermatol. Res. 2010, 302, 419-428. [CrossRef]

51. Krzystek-Korpacka, M.; Kędzior, K.; Masłowski, L.; Mierzchała, M.; Bednarz-Misa, I.; Bronowicka-Szydełko, A.; Kubiak, J.; Gacka, M.; Płaczkowska, S.; Gamian, A. Impact of chronic wounds of various etiology on systemic profiles of key inflammatory cytokines, chemokines and growth factors, and their interplay. Adv. Clin. Exp. Med. 2019, 28, 1301-1309. [CrossRef] [PubMed]

52. Guilloteau, K.; Paris, I.; Pedretti, N.; Boniface, K.; Juchaux, F.; Huguier, V.; Guillet, G.; Bernard, F.-X.; Lecron, J.-C.; Morel, F. Skin inflammation induced by the synergistic action of IL-17A, IL-22, oncostatin M, IL- $1 \alpha$, and TNF- $\alpha$ recapitulates some features of psoriasis. J. Immunol. 2010, 184, 5263-5270. [CrossRef]

53. Van der Zee, H.; de Ruiter, L.; Van Den Broecke, D.; Dik, W.; Laman, J.; Prens, E. Elevated levels of tumour necrosis factor (TNF)- $\alpha$, interleukin (IL)-1 $\beta$ and IL-10 in hidradenitis suppurativa skin: A rationale for targeting TNF- $\alpha$ and IL-1 $\beta$. Br. J. Dermatol. 2011, 164, 1292-1298. [CrossRef] [PubMed]

54. Ozkanli, S.; Karadag, A.S.; Ozlu, E.; Uzuncakmak, T.K.; Takci, Z.; Zemheri, E.; Zindanc1, I.; Akdeniz, N. A comparative study of MMP-1, MMP-2, and TNF- $\alpha$ expression in different acne vulgaris lesions. Int. J. Dermatol. 2016, 55, 1402-1407. [CrossRef] [PubMed]

55. Dréno, B. What is new in the pathophysiology of acne, an overview. J. Eur. Acad. Dermatol. Venereol. 2017, 31, 8-12. [CrossRef] [PubMed]

56. Kanlayavattanakul, M.; Lourith, N. Therapeutic agents and herbs in topical application for acne treatment. Int. J. Cosmet. Sci. 2011, 33, 289-297. [CrossRef]

57. Johnson, B.Z.; Stevenson, A.W.; Prêle, C.M.; Fear, M.W.; Wood, F.M. The role of IL-6 in skin fibrosis and cutaneous wound healing. Biomedicines 2020, 8, 101. [CrossRef]

58. Nishikai-Yan Shen, T.; Kanazawa, S.; Kado, M.; Okada, K.; Luo, L.; Hayashi, A.; Mizuno, H.; Tanaka, R. Interleukin-6 stimulates Akt and p38 MAPK phosphorylation and fibroblast migration in non-diabetic but not diabetic mice. PLoS ONE 2017, 12, e0178232. [CrossRef] [PubMed]

59. Lee, Y.; Kim, S.; Yang, B.; Lim, C.; Kim, J.-H.; Kim, H.; Cho, S. Anti-inflammatory effects of Brassica oleracea Var. capitata L.(Cabbage) methanol extract in mice with contact dermatitis. Pharmacogn. Mag. 2018, 14, 174.

60. Huang, W.-C.; Tsai, T.-H.; Huang, C.-J.; Li, Y.-Y.; Chyuan, J.-H.; Chuang, L.-T.; Tsai, P.-J. Inhibitory effects of wild bitter melon leaf extract on Propionibacterium acnes-induced skin inflammation in mice and cytokine production in vitro. Food Funct. 2015, 6, 2550-2560. [CrossRef] [PubMed]

61. Lobmann, R.; Ambrosch, A.; Schultz, G.; Waldmann, K.; Schiweck, S.; Lehnert, H. Expression of matrix-metalloproteinases and their inhibitors in the wounds of diabetic and non-diabetic patients. Diabetologia 2002, 45, 1011-1016. [CrossRef]

62. Kanno, E.; Tanno, H.; Masaki, A.; Sasaki, A.; Sato, N.; Goto, M.; Shisai, M.; Yamaguchi, K.; Takagi, N.; Shoji, M. Defect of interferon $\gamma$ leads to impaired wound healing through prolonged neutrophilic inflammatory response and enhanced MMP-2 activation. Int. J. Mol. Sci. 2019, 20, 5657. [CrossRef]

63. Fujiwara, M.; Muragaki, Y.; Ooshima, A. Keloid-derived fibroblasts show increased secretion of factors involved in collagen turnover and depend on matrix metalloproteinase for migration. Br. J. Dermatol. 2005, 153, 295-300. [CrossRef]

64. Ulrich, D.; Ulrich, F.; Unglaub, F.; Piatkowski, A.; Pallua, N. Matrix metalloproteinases and tissue inhibitors of metalloproteinases in patients with different types of scars and keloids. J. Plast Reconstr Aesthet Surg 2010, 63, 1015-1021. [CrossRef] [PubMed]

65. Del Duca, E.; Morelli, P.; Bennardo, L.; Di Raimondo, C.; Nisticò, S.P. Cytokine pathways and investigational target therapies in Hidradenitis suppurativa. Int. J. Mol. Sci. 2020, 21, 8436. [CrossRef] [PubMed]

66. Sanchez, J.; Le Jan, S.; Muller, C.; François, C.; Renard, Y.; Durlach, A.; Bernard, P.; Reguiai, Z.; Antonicelli, F. Matrix remodelling and MMP expression/activation are associated with hidradenitis suppurativa skin inflammation. Exp. Dermatol. 2019, 28, 593-600. [CrossRef] [PubMed]

67. Marzano, A.; Damiani, G.; Ceccherini, I.; Berti, E.; Gattorno, M.; Cugno, M. Autoinflammation in pyoderma gangrenosum and its syndromic form (pyoderma gangrenosum, acne and suppurative hidradenitis). Br. J. Dermatol. 2017, 176, 1588-1598. [CrossRef]

68. Choi, J.-Y.; Piao, M.S.; Lee, J.-B.; Oh, J.S.; Kim, I.-G.; Lee, S.-C. Propionibacterium acnes stimulates pro-matrix metalloproteinase-2 expression through tumor necrosis factor- $\alpha$ in human dermal fibroblasts. J. Investig. Dermatol. 2008, 128, 846-854. [CrossRef] [PubMed]

69. Mozeika, E.; Pilmane, M.; Nürnberg, B.M.; Jemec, G.B. Tumour necrosis factor-alpha and matrix metalloproteinase-2 are expressed strongly in hidradenitis suppurativa. Acta Derm. Venereol. 2013, 93, 301-304. [CrossRef]

70. Manosroi, A.; Chankhampan, C.; Kietthanakorn, B.O.; Ruksiriwanich, W.; Chaikul, P.; Boonpisuttinant, K.; Sainakham, M.; Manosroi, W.; Tangjai, T.; Manosroi, J. Pharmaceutical and cosmeceutical biological activities of hemp (Cannabis sativa L. var. sativa) leaf and seed extracts. Chiang Mai J. Sci. 2019, 46, 180-195.

71. Ruksiriwanich, W.; Sirithunyalug, J.; Boonpisuttinant, K.; Jantrawut, P. Potent in vitro collagen biosynthesis stimulating and antioxidant activities of edible mushroom Volvariella volvacea aqueous extract. Int. J. Pharm. Pharm. Sci. $2014,6,406-412$. 
72. Vuong, T.T.; Rønning, S.B.; Ahmed, T.A.; Brathagen, K.; Høst, V.; Hincke, M.T.; Suso, H.-P.; Pedersen, M.E. Processed eggshell membrane powder regulates cellular functions and increase MMP-activity important in early wound healing processes. PLoS ONE 2018, 13, e0201975. [CrossRef]

73. Thompson, J.D.; Gibson, T.J.; Higgins, D.G. Multiple sequence alignment using ClustalW and ClustalX. Curr. Protoc. Bioinform. 2003, 2, 2.3.1-2.3.22. [CrossRef]

74. Kumar, S.; Stecher, G.; Li, M.; Knyaz, C.; Tamura, K. MEGA X: Molecular evolutionary genetics analysis across computing platforms. Mol. Biol. Evol. 2018, 35, 1547. [CrossRef] [PubMed]

75. Lux, P.E.; Freiling, M.; Stuetz, W.; von Tucher, S.; Carle, R.; Steingass, C.B.; Frank, J. (Poly) phenols, carotenoids, and tocochromanols in corn (Zea mays L.) kernels as affected by phosphate fertilization and sowing time. J. Agric. Food Chem. 2020, 68, 612-622. [CrossRef] [PubMed]

76. Ruksiriwanich, W.; Khantham, C.; Sringarm, K.; Sommano, S.; Jantrawut, P. Depigmented Centella asiatica extraction by pretreated with supercritical carbon dioxide fluid for wound healing application. Processes 2020, 8, 277. [CrossRef]

77. Khantham, C.; Yooin, W.; Sringarm, K.; Sommano, S.R.; Jiranusornkul, S.; Carmona, F.D.; Nimlamool, W.; Jantrawut, P.; Rachtanapun, P.; Ruksiriwanich, W. Effects on steroid 5-alpha reductase gene expression of Thai rice bran extracts and molecular dynamics study on SRD5A2. Biology 2021, 10, 319. [CrossRef]

78. Ko, W.-K.; Lee, S.-H.; Kim, S.J.; Jo, M.-J.; Kumar, H.; Han, I.-B.; Sohn, S. Anti-inflammatory effects of ursodeoxycholic acid by lipopolysaccharide-stimulated inflammatory responses in RAW 264.7 macrophages. PLoS ONE 2017, 12, e0180673. [CrossRef] [PubMed] 